\title{
The Synthesis of Agar Silicone Biocomposite and Its Mechanical Properties
}

\author{
Nurul Nadiah Azmi ${ }^{* *}$, Jamaluddin Mahmud ${ }^{2,3}$, Mohd Juzaila Abd Latif ${ }^{4}$ \\ ${ }^{1}$ Faculty of Mechanical Engineering, Universiti Teknologi MARA, Pulau Pinang, Malaysia \\ ${ }^{2}$ Faculty of Mechanical Engineering, Universiti Teknologi MARA, Shah Alam, Selangor, Malaysia \\ ${ }^{3}$ Biomechanical and Clinical Engineering (BioMeC) Research Group, Universiti Teknologi MARA, Shah Alam, Selangor,40450, Malay- \\ sia \\ ${ }^{4}$ Faculty of Mechanical Engineering, Universiti Teknikal Malaysia Melaka, Hang Tuah Jaya, 76100 Durian Tunggal Melaka, Malaysia \\ *Corresponding author E-mail: nadiah85@uitm.edu.my
}

\begin{abstract}
Silicone rubber is widely used in the medical field, whereas agar is widely used as a medium to breed bacteria or to carry the active ingredient for a specific purpose. There are few synthetic skins available in the market that are made of silicone, such as Biobrane, Integra and Transcyte, to name a few. Meanwhile, in a previous study, agar is used to carry the active ingredients in turmeric to the wounded skin and expedite its recovery. However, up to date, there is no available skin substitute with the ability for carrying bioactive ingredient that would expedite wound healing and anti-bacterial properties. Hence, this study aims to synthesise a new biocomposite that could mimic skin mechanical properties with the future potential to carry bioactive ingredient via agar particles. The material constants for this newly developed agar slicone biocomposite are determined using Neo- Hookean, Mooney-Rivlin and Ogden models. This research consists of two main stages; which is the synthesis and the determination of the mechanical properties of agar silicone biocomposite, via experimental and numerical approach. The experimental approach involves testing the biocomposite under uniaxial tensile test, while the numerical approach involves curve fitting method using a Matlab programme. The calculated parameter for NeoHookean (C1) ranges from 52-57 kPa for all variances of agar silicone biocomposite. As for Mooney-Rivlin, the values are of 34-38 kPa and 47- $54 \mathrm{kPa}$ for $\mathrm{C} 1$ and $\mathrm{C} 2$ re spectively. Ogden parameters (Ogden coefficient, $\mu$ and Ogden exponent, $\alpha$ ) for agar silicone biocomposites are 48-54 kPa; 2.17-2.19 $(\mu ; \alpha)$. The material constants of agar silicone biocomposites lays within the range of human tissue and skin, as well as animal skin; thus proving that agar silicone biocomposite could deform nearly the same as skin. Therefore, it can be concluded that this study has significant contribution to better understand the mechanical properties of the newly developed agar silicone biocomposite.
\end{abstract}

Keywords: synthesise; silicone rubber; biocomposite; agar; silicone

\section{Introduction}

Silicone rubber or polysiloxanes or polydimethylsiloxane is categorised as a synthetic polymer [1,2]. It comprises of $\mathrm{Si}-\mathrm{O}$ backbone bonded with organic groups $(\mathrm{R})$ and behaves like a natural rubber. Polydimethylsiloxanes which are also abbreviated as PDMS is the most used silicone rubber and also the foundation of all silicone. Silicone is used in contact lenses since 1998, since it allows oxygen permeability into the eye, compared to the conventional hydrogel contact lenses [3]. A study by Jinping Hou uses nylon and silicone rubber (Ecoflex 0030), to imitate the deformation of octopus skin, for an octopus inspired robot [4]. The results, however, showed a smaller deformation compared to the real octopus skin. Silicone is also gaining popularity in the medical field as aesthetic implants (testical implant, breast implant and nose implant), orthopaedic implants (the socket in hip joint, finger joint), medical disposable supplies (needle, syringe, catheter, extracorporeal equipment, shunt, drains and tubes), and dental implants. Besides that, silicone is also used as one of the main substance in synthetic skin substitutes, such as Biobrane ${ }^{\circledR}$ Integra $^{\circledR}$ and TransCyte ${ }^{\circledR}$. The synthetic skins are grouped into two categories:1) according to the time it is used (temporary or permanent skin substitutes) and 2) according to the type of material used (biological or synthetic skin substitutes).

Agar is composed of alternating 1,3-linked-D -galactose and 1,4linked 3,6-anhydro-L-galactose units. It is easily accessible, and been used extensively in the food industry, as it has high gelling ability[5]. In a study by [6], the film prepared from agar alone have low tensile strength, brittle, as well as being sticky and difficult to handle, whilst film prepared from agar and gelatin is nonsticky, but very stiff. The value of the tensile strength for agargelatin film was not mentioned in the paper. Thus, the agar- based control film in the study consist of agar-gelatin-glycerol-propylene glycol (AGGP), where glycerol and propylene glycol act as the plasticizers to the polymeric film. Plasticizers are added to the agar-gelatin film to reduce its brittleness, since it works as spacers between the polymeric chain and increases its flexibility and extensibility of polymers. The turmeric extracts were then impregnated into the AGGP film. Turmeric was used extensively as medicine in earlier days, as it has antimicrobial, antioxidant and wound healing properties [6]. The turmeric extract in [6] provides suitable microenvironment to the wound, where it was observed that it has lesser bacterial growth (compared to the control film) and accelerates the healing process. 
However, to date, there is no available skin substitute with the ability for carrying bioactive ingredient that would expedite wound healing and anti-bacterial properties.

Hence, this study aims to synthesise a new biocomposite that could mimic skin mechanical properties with the future potential to carry bioactive ingredient via agar particles. The material constants for this newly developed agar slicone biocomposite are determined using Neo- Hookean, Mooney-Rivlin and Ogden models. This is novel as the mechanical properties of agar silicone bicomposite have not been reported before.

\section{Materials and Method}

This research consists of two main steps in order to obtain the material constant of agar silicone biocomposite, which were the synthesis process and the determination of the material constants. In order to determine the material constants; two approaches are used; 1) experimental approach (which is the uniaxial tensile test) and 2) numerical approach. Numerical approach was used because the raw data from tensile test alone could not determine the material constants of agar silicone biocomposites. The mechanical properties of this biocomposite is the material constant parameters in the hyperelastic constitutive models. Figure 1 shows the overall flow of the processes involved in this study.

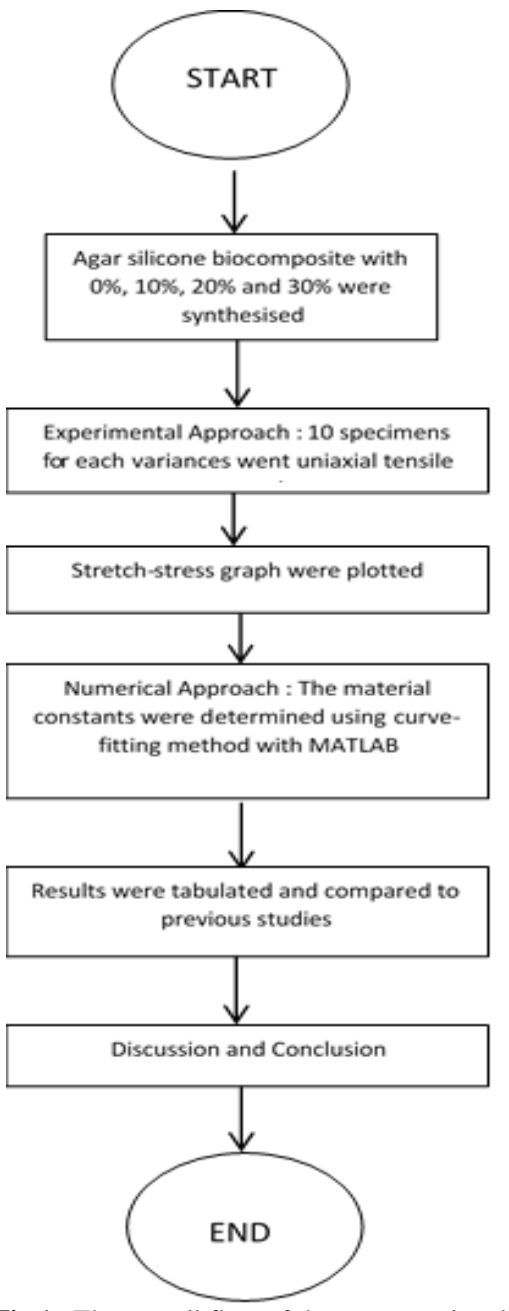

Fig 1 : The overall flow of the processes involved in this study.

The materials that were used in this research were agar powder and platinum cured soft silicone Ecoflex 0030. Silicone Ecoflex 0030 were obtained from the sole distributor of Smooth-On in Malaysia, Castmech Sdn Bhd. Silicone Ecoflex came in liquid form with two parts; Part A and B. Both parts were mixed with the ratio of $1 \mathrm{~A}: 1 \mathrm{~B}$. After mixing,the silicone was poured into the beaker that contains agar powder.

Agar powder was obtained from a local grocery store. The amount of agar needed for each biocomposite variances were calculated. The desired weight of agar powder for 10, 20 and 30\% variances were $0.7 \mathrm{~g}, 1.4 \mathrm{~g}$ and $2.1 \mathrm{~g}$ respectively.

The agar and silicone mixture were mixed and stirred using a spatula. The stirring process was essential to ensure the final product to be homogenous. Secondly, the bubbles in the mixture was removed using MCP vacuum casting system machine, before pouring it into the aluminium mold. Lastly, the agar silicone in the mold was cured in the oven at $73^{\circ} \mathrm{C}$. The same process was repeated until ten specimens were obtained for each variance. Figures 2-1 till 2-4 show the step by step sample preparation.

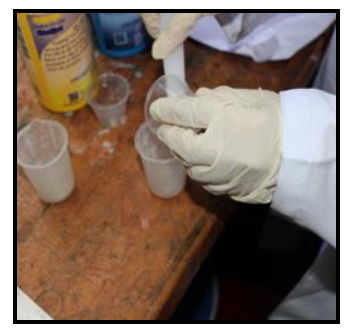

$$
\begin{aligned}
& \text { 2-1. Stirring process of } \\
& \text { agar silicone } \\
& \text { biocomposite }
\end{aligned}
$$

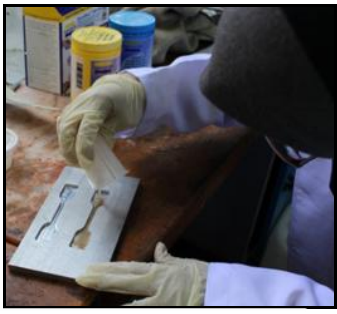

2-3. Pouring the mix ture into the mold

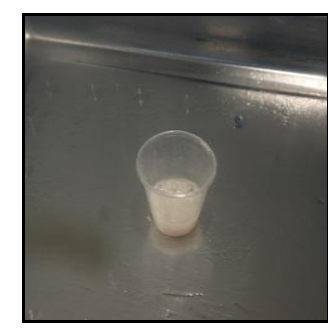

2-2. Bubble removal using vacuum casting system

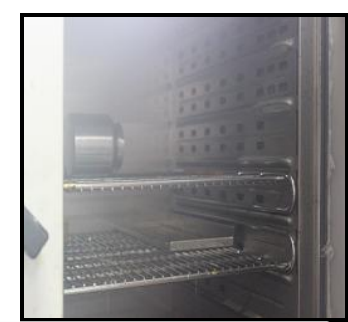

2-4. Curing process in the oven
Then, the agar silicone biocomposite underwent uniaxial tensile testing. The biocomposite were assumed to be hyperleastic, incompressible and isotropic. Equations 1, 2 and 3 were hyperelastic equations for incompressible and isotropic materials in terms of elastic strain density function, $W$. Equation 1 is the Neo-Hookean model, equation 2 is Mooney-Rivlin model and equation 3 is $\mathrm{Og}$ den model.

However, the raw data obtained from the uniaxial tensile test were engineering stress-strain $\left(\sigma_{\mathrm{E}}-\varepsilon\right)$. Thus, equations 1,2 and 3 were manipulated to yield the engineering stress $\sigma_{\mathrm{E}}$ and stretch, $\lambda$ equations (equations 4,5 and 6 respectively) in order to simplify the calculations. The values of stretch, $\lambda$ can be calculated from the strain values [13] and the engineering stress-stretch graphs were plotted. These curves are known as the reference curves.

The next step was the curve fitting procedure using equations 4,5 , and 6 to get the best match curve to the reference curve. This best match curve will give the value of the material constants parameters in the equations. The material constants are $\mathrm{C} 1$ for NeoHookean (1 and 4), C1 and C2 for Mooney-Rivlin (2 and 5) and $\alpha$ and $\mu$ for Ogden (3 and 6). These material constants represent the mathematical parameters in the equations of the hyperelastic models which describes the mechanical behaviour of the biocomposites.

$\mathrm{W}=\mathrm{C}_{1}\left(\mathrm{I}_{1}-3\right)$

$\mathrm{W}=\mathrm{C}_{1}\left(\mathrm{I}_{1}-3\right)+\mathrm{C}_{2}\left(\mathrm{I}_{2}-3\right)$ 


$$
W=\sum_{i=1}^{N} \frac{\mu_{i}}{\alpha_{i}}\left(\lambda_{1}^{\alpha_{i}}+\lambda_{2}^{\alpha_{i}}+\lambda_{3}^{\alpha_{i}}-3\right)
$$

Equations (4), (5) and (6) below show the engineering stress, $\sigma_{\mathrm{E}}$ as a function of stretch, $\lambda$, which are the simplifications of equations 1,2 and 3 .

$$
\begin{aligned}
& \sigma_{\mathrm{E}}=\left(2 \mathrm{C}_{1}\right)\left(\lambda-\frac{1}{\lambda^{2}}\right) \\
& \sigma_{\mathrm{E}}=\frac{1}{\lambda}\left[\left(2 \mathrm{C}_{1}+\frac{2 \mathrm{C}_{2}}{\lambda}\right)\left(\lambda^{2}-\frac{1}{\lambda}\right)\right] \\
& \sigma_{\mathrm{E}}=\frac{\mu}{\lambda}\left(\lambda^{\alpha}-\lambda^{-\alpha / 2}\right)
\end{aligned}
$$

\section{Results and Discussion}

After obtaining the material constants from the curve fitting procedure, the results were tabulated. Table 3.1 shows the value of the material constants for all three hyperelastic constitutive models, Neo-Hookean, Mooney Rivlin and Ogden. The results show that the value of the material constant increases as the reinforcement material increases. This is true for all the three constitutive models in agar silicone biocomposite. Another observation that can be made is the decreasing tensile strength of the biocomposite as the reinforcement material increases. These are shown in Fig 3.1 to Fig 3.3 where the stress to fail decreases slightly as the filler of the biocomposite increases. This is due to the presence of the weak adhesive bond between the matrix and its filler. The drying process of the silicone biocomposite in the oven at $73^{\circ} \mathrm{C}$ has reduces

\begin{tabular}{|c|c|c|c|c|}
\hline \multicolumn{2}{|c|}{ Variances } & \multicolumn{3}{|c|}{ Material Constants (MPa) } \\
\hline & & $\begin{array}{l}\text { Neo- } \\
\text { Hookean }\end{array}$ & Mooney-Rivlin & Ogden \\
\hline \multirow[t]{4}{*}{$\begin{array}{l}\text { Agar } \\
\text { silicone }\end{array}$} & $0 \%$ & $\mathrm{C} 1=0.028$ & $\begin{array}{l}\mathrm{C} 1=0.033 \\
\mathrm{C} 2=0.005\end{array}$ & $\begin{array}{l}\alpha=2.170 \\
\mu=0.046 \mathrm{MPa}\end{array}$ \\
\hline & $10 \%$ & $\mathrm{C} 1=0.052$ & $\begin{array}{l}\mathrm{C} 1=0.034 \\
\mathrm{C} 2=0.047\end{array}$ & $\begin{array}{l}\alpha=2.450 \\
\mu=0.046 \mathrm{MPa}\end{array}$ \\
\hline & $20 \%$ & $\mathrm{C} 1=0.053$ & $\begin{array}{l}\mathrm{C} 1=0.035 \\
\mathrm{C} 2=0.048\end{array}$ & $\begin{array}{l}\alpha=2.452 \\
\mu=0.049 \mathrm{MPa}\end{array}$ \\
\hline & $30 \%$ & $\mathrm{C} 1=0.057$ & $\begin{array}{l}\mathrm{C} 1=0.038 \\
\mathrm{C} 2=0.054\end{array}$ & $\begin{array}{l}\alpha=2.588 \\
\mu=0.049 \mathrm{MPa}\end{array}$ \\
\hline
\end{tabular}
the moisture in the silicone biocomposite, hence reducing the stretchiness of the material.

Table 3.1: The material constants for all specimens

Fig 3.1 shows the stress stretch relationship of agar silicone biocomposite that adapts Neo-Hookean model.

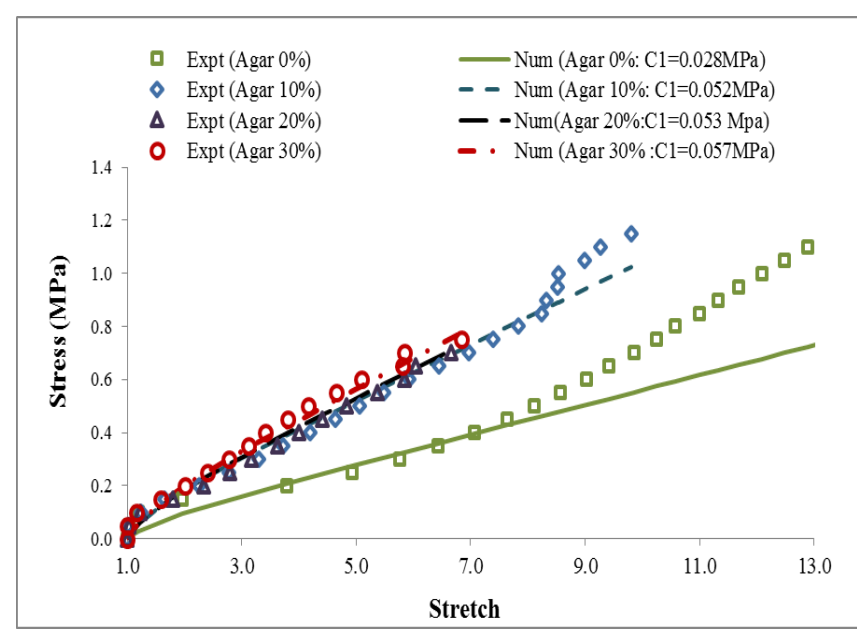

Fig 3.1: The stress stretch relationship of agar silicone biocomposite adapting Neo-Hookean model.
Fig 3.2 is the stress stretch relationship of agar silicone bioomposite that adapts Mooney-Rivlin model. Both values of $\mathrm{C} 1$ and $\mathrm{C} 2$ increases as the reinforcement material increases. The stress stretch lines were farther from the experimental stress stretch lines.

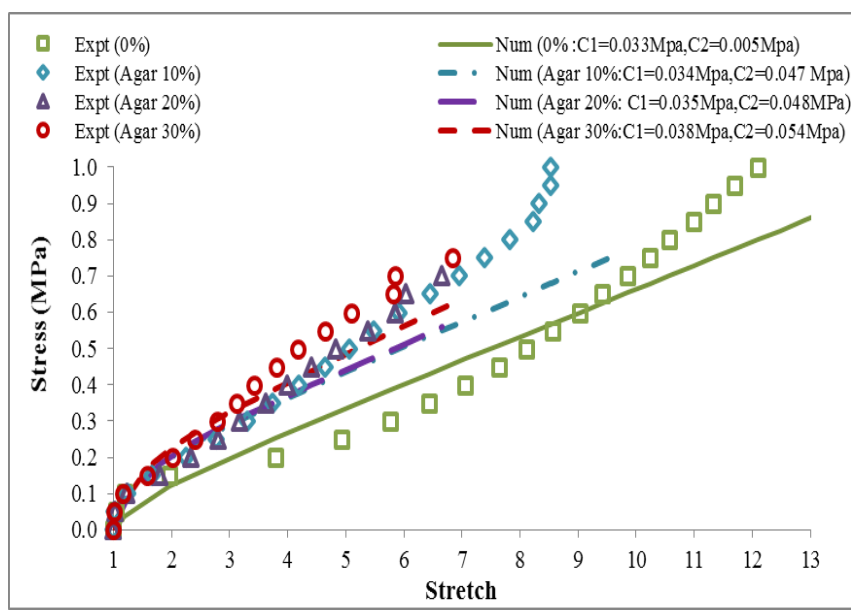

Fig 3.2: The stress stretch relationship of agar silicone biocomposite adapting Mooney Rivlin model

Figure 3.3 shows the stress stretch relationship of agar silicone biocomposite that adapts Ogden model.

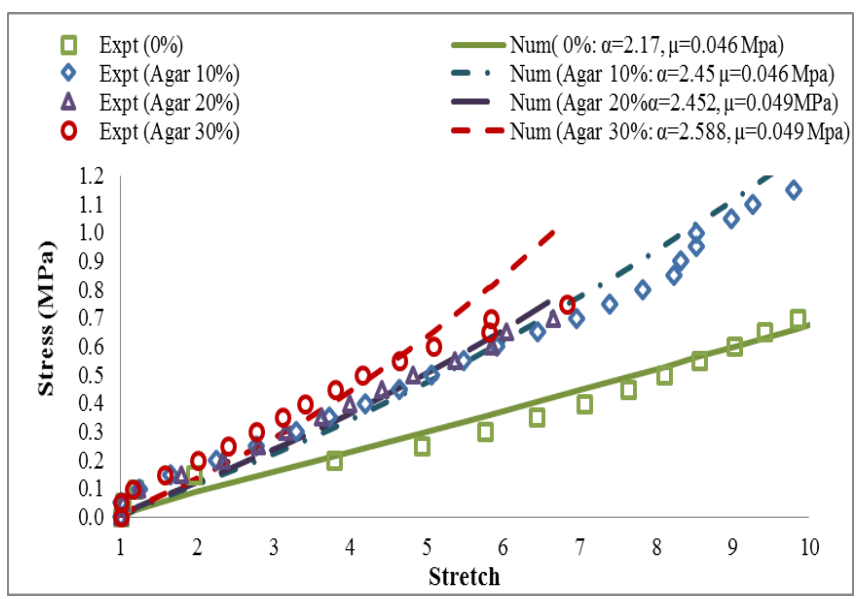

Fig 3.3: The stress stretch relationship of agar silicone biocomposite adapting Ogden model

Figure 3.4 and Figure 3.5 show the numerical method graphs using the material constants for all three hyperelastic constitutive models, Neo-Hookean, Mooney Rivlin and Ogden relative to the experimental method. These two graphs indicate that MooneyRivlin and Neo-Hookean constitutive model best describes the hyperelastic properties of agar silicone biocomposite.

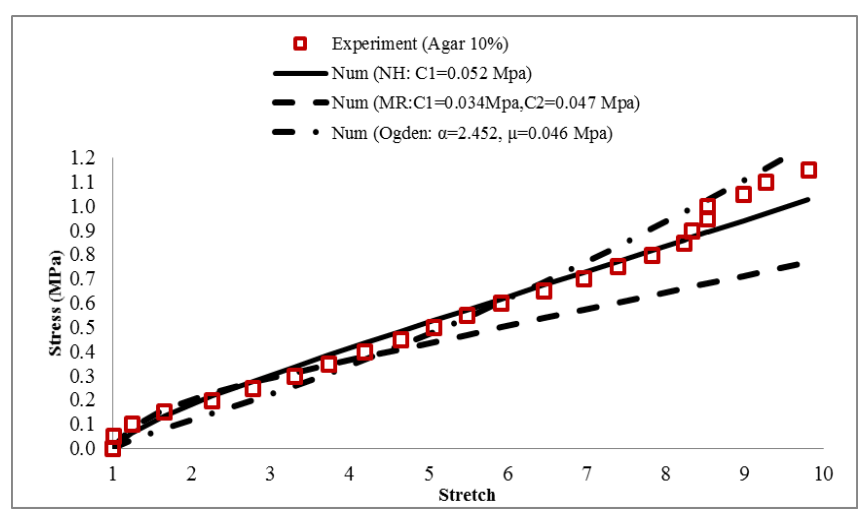

Fig 3.4: The stress stretch relationship of $10 \%$ agar silicone biocomposite adapting Neo-Hookean, Mooney-Rivlin and Ogden model. 


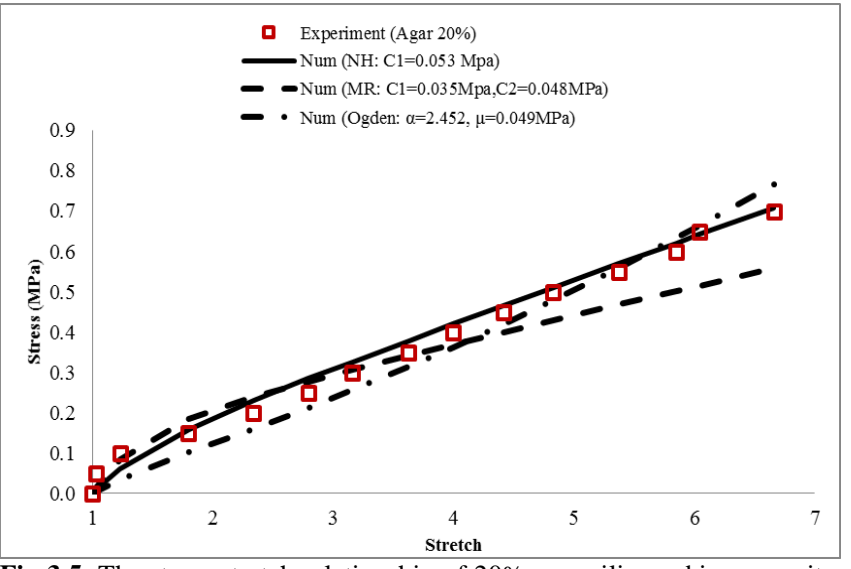

Fig 3.5: The stress stretch relationship of $20 \%$ agar silicone biocomposite adapting Neo-Hookean, Mooney-Rivlin and Ogden model.

A study on chloropene rubber showed that Mooney-Rivlin and Ogden model best described the material in a specific ranges for isotropic hyperelastic model [17]. Ogden model are more complex and thus more suitable for large deformations, compared to Mooney-Rivlin. Both Mooney-Rivlin and Neo-Hookean are more suitable for a simple check in small strain range.

Table 3.2 until Table 3.4 compare the results obtained from this study to the previous findings under uniaxial tensile test. Table 3.2 illustrates the comparison of the material constants that adapts the Neo-Hookean model (C1) from previous studies to the current research. Meanwhile, Table 3.3 depicts the comparison of former study that adapts the Mooney-Rivlin model to this research. Lastly, Table 3.4 is the comparison of Ogden material properties ( $\mu$ and $\alpha$ ) of soft tissues and other hyperelastic materials under tensile test. From these three tables, the determined parameter for NeoHookean (C1) ranges from $52-57 \mathrm{kPa}$ for agar silicone biocomposite. As for Mooney-Rivlin, the parameters for agar silicone has the value of $34-38 \mathrm{kPa}$ and $47-54 \mathrm{kPa}$ for $\mathrm{C} 1$ and $\mathrm{C} 2$ respectively. Ogden parameters (Ogden coefficient, $\mu$ and Ogden exponent, $\alpha$ ) for agar silicone are $48-54 \mathrm{kPa} ; 2.17-2.19(\mu ; \alpha)$. The material constant increases with the increase of reinforcement material. Agar silicone biocomposites are softer than fresh animal skin such as bovine and goat ( as the value of the material constants are lower), but the values are in between the material constants of orbital fat and connective tissue (OFCT) of the eye and human skin in tension.

There are studies by Mahmud, L., et al., and Mahmud, J. et al., on human skin using finite element method to obtain Ogden parameters $[8,9]$. The studies concluded that the value for $\mu=26$ $\mathrm{Pa}, \alpha=110$ and $\mu=10 \mathrm{~Pa}, \alpha=40$ respectively. Both studies showed a lower value of Ogden shear modulus compared to agar silicone biocomposite.

Table 3.2: Comparison of Neo-Hookean material properties from previous study to this research

\begin{tabular}{|c|c|c|c|}
\hline $\mathrm{C}_{1}$ & Specimen & Test Type & Reference \\
\hline $5 \mathrm{kPa}$ & Pulmonary Artery Tissue & Tension & {$[10]$} \\
\hline $\begin{array}{l}0.8 \text { to } 1.7 \mathrm{kPa} \\
2.1 \text { to } 3.5 \mathrm{kPa}\end{array}$ & 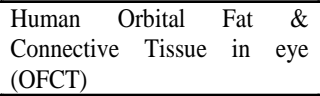 & Tension & [11] \\
\hline 2.1 to $3.5 \mathrm{kPa}$ & 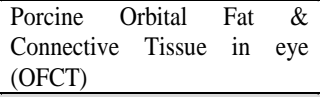 & Tension & [11] \\
\hline 52 to $57 \mathrm{kPa}$ & Agar silicone Biocomposites & Uniaxial tension & $\begin{array}{l}\text { CURRENT } \\
\text { STUDY }\end{array}$ \\
\hline $\begin{array}{ll}123.8 \text { to } 142.1 \\
\mathrm{kPa}\end{array}$ & Elastin & Tension & [12] \\
\hline $0.651-1 \mathrm{MPa}$ & Thin Polymer Layers & Tension & [13] \\
\hline $3.98-4.58 \mathrm{MPa}$ & Fresh goat skin unshaved & Tension & [14] \\
\hline $6.81-8.51 \mathrm{MPa}$ & Fresh goat skin shaved & Tension & [14] \\
\hline $\begin{array}{l}14.23-24.67 \\
\mathrm{MPa}\end{array}$ & Goat Leather & Tension & [14] \\
\hline $21.88 \mathrm{MPa}$ & Bovine Leather & Tension & [14] \\
\hline
\end{tabular}

Table 3.3: Comparison of Mooney-Rivlin material properties from previous study to this research

\begin{tabular}{|c|c|c|c|c|}
\hline $\mathrm{C}_{1}$ & $\mathrm{C}_{2}$ & Specimen & Test Types & Reference \\
\hline $\begin{array}{l}-11.2 \text { to }- \\
7.1 \mathrm{kPa}\end{array}$ & $\begin{array}{l}10.1 \text { to } 16.1 \\
\mathrm{kPa}\end{array}$ & $\begin{array}{l}\text { Porcine Orbital Fat \& } \\
\text { Connective Tissue in } \\
\text { eye(OFCT) }\end{array}$ & Tension & [11] \\
\hline $\begin{array}{l}-5.0 \text { to }-2.7 \\
\mathrm{kPa}\end{array}$ & $\begin{array}{l}3.8 \text { to } 7.1 \\
\mathrm{kPa}\end{array}$ & $\begin{array}{l}\text { Human Orbital Fat \& } \\
\text { Connective Tissue in } \\
\text { eye(OFCT) }\end{array}$ & Tension & [11] \\
\hline $17.97 \mathrm{kPa}$ & $11.3 \mathrm{kPa}$ & Nylon+silicone (Ecoflex) & Tension & [4] \\
\hline $\begin{array}{l}34 \text { to } 38 \\
\mathrm{kPa}\end{array}$ & 47 to $54 \mathrm{kPa}$ & $\begin{array}{ll}\text { Agar } & \text { silicone } \\
\text { Biocomposites } & \\
\end{array}$ & $\begin{array}{l}\text { Uniaxial } \\
\text { Tension }\end{array}$ & $\begin{array}{l}\text { CURRENT } \\
\text { STUDY }\end{array}$ \\
\hline $0.3 \mathrm{MPa}$ & $0 \mathrm{MPa}$ & Human Skin & Tension & [13] \\
\hline $0.5 \mathrm{MPa}$ & $0 \mathrm{MPa}$ & Silicone Rubber (B452) & Tension & [13] \\
\hline $1.0 \mathrm{MPa}$ & $0.9 \mathrm{MPa}$ & $\begin{array}{ll}\begin{array}{l}\text { Silicone } \\
(\text { Sil8800) }\end{array} & \text { Rubber } \\
\end{array}$ & Tension & [11] \\
\hline $\begin{array}{l}74.51 \text { to } \\
96.57 \mathrm{MPa}\end{array}$ & $\begin{array}{l}-88.61 \text { to }- \\
109.24 \mathrm{MPa}\end{array}$ & Fresh goat skin shaved & $\begin{array}{l}\text { Uniaxial } \\
\text { Tension }\end{array}$ & [14] \\
\hline
\end{tabular}

Table 3.4: Comparison of Ogden material properties from previous study

\begin{tabular}{lllll}
$\begin{array}{l}\text { Shear } \\
\text { Modulus, } \\
\boldsymbol{\mu}\end{array}$ & $\begin{array}{l}\text { Strain } \\
\text { hardening } \\
\text { component, } \\
\boldsymbol{\alpha}\end{array}$ & Specimen & Test Type & Reference \\
\hline $10 \mathrm{~Pa}$ & 110 & $\begin{array}{l}\text { Human Skin (ventral } \\
\text { forearm) }\end{array}$ & Tension & {$[15]$} \\
\hline 48 to $54 \mathrm{kPa}$ & 2.169 to & $\begin{array}{l}\text { Agar silicone } \\
\text { Biocomposites }\end{array}$ & $\begin{array}{l}\text { Uniaxial } \\
\text { Tension }\end{array}$ & $\begin{array}{l}\text { CURRENT } \\
\text { STUDY }\end{array}$ \\
\hline $0.11 \mathrm{MPa}$ & 9 & Human Skin & $\begin{array}{l}\text { Uniaxial } \\
\text { Tension }\end{array}$ & {$[16]$} \\
\hline 0.153 to 0.18 & 15.15 to & $\begin{array}{l}\text { Fresh goat skin } \\
\text { unshaved }\end{array}$ & $\begin{array}{l}\text { Uniaxial } \\
\text { Tension }\end{array}$ & {$[14]$} \\
$\mathrm{MPa}$ & 18.34 & $\begin{array}{l}\text { Fresh goat skin } \\
\text { shaved }\end{array}$ & $\begin{array}{l}\text { Uniaxial } \\
\text { Tension }\end{array}$ & {$[14]$} \\
\hline 0.152 to 0.277 & 16.16 to & Goat leather & $\begin{array}{l}\text { Uniaxial } \\
\text { tension }\end{array}$ & {$[14]$} \\
$\mathrm{MPa}$ & 17.31 & Bovine leather & $\begin{array}{l}\text { Uniaxial } \\
\text { tension }\end{array}$ & {$[14]$} \\
\hline $1.827 \mathrm{MPa}$ & 15.89 & & & \\
\hline $3.50 \mathrm{MPa}$ & 14.82 & & & \\
\hline
\end{tabular}

\section{Conclusions}

In conclusion, this research has succesfully shown the synthesising process of the newly developed agar silicone biocomposite and determined its Neo-Hookean, Mooney-Rivlin and Ogden material constants and coefficients respectively. This is novel as the mechanical properties of agar silicone biocomposite have not been reported earlier. It is interesting to find that the material constants of agar silicone biocomposites lays within the range of human tissue and skin, as well as animal skin. This proves that agar silicone biocomposite could deform nearly the same as skin. This study will lead to the development of a new synthetic skin with the ability to carry bioactive ingredients for would healing application.

\section{Acknowledgement}

This research is funded by the Ministry of Higher Education (MOHE) Malaysia and Universiti Teknologi MARA Malaysia, grant no. FRGS/1/2016/TK03/UITM/02/6 (UiTM File. No. 600RMI/FRGS 5/3 (0098/2016)). The authors gratefully acknowledge the financial support.

\section{References}

[1] Azmi NN ,Hussain AK and Mahmud J, Kenaf Silicone Biocomposites: Synthesis and its Hyperelastic Behaviour Materials Science Forum, Vol. 900, pp. 12-16, 2017

[2] Jankauskaitė V., Abzalbekuly B., Lisauskaitė A., Procyčevas I., Fataraitė E., Vitkauskienė A., Janakhmetov U. Silicone Rubber and 
Microcrystalline Cellulose Composites with Antimicrobial Properties Materials Science (MEDŽIAGOTYRA) Vol. 20, No. 1. 2014

[3] Guillon M \& Maissa C. Use Of Silicone Hydrogel Material For Daily Wear Contact Lens \& Anterior Eye 30 p. 5-10, 2007

[4] Hou J, Bonser RHC, Jeronimidis G. Design of a Biomimetic Skin for an Octopus-Inspired Robot- Part II: Development of the Skin Artefact Journal of Bionic Engineering, vol 8: p. 297-304, 2011.

[5] Wu Y, Geng F,Chang PR, Yu J, Ma X. Effect of Agar on the Microstructure and Performance of Potato Starch Film, Carbohydrate Polymers, vol 76: p.299-304, 2009.

[6] Saraswathy N, Rohit R, Shanmugam K, Sozeeswari SC, Ramalingam P. A Preliminary Investigation of Turmeric-Agar composite film as bioactive Wound Dressing mmaterial on Excision Wound in Rat Model Journal of Natural Products and Resources, Vol. 3(2), p. 237-241, 2012.

[7] Mahmud L, Adull Manan NF, Ismail MH, Mahmud J. Characterisation of Soft Tissues Biomechanical Properties Using 3D Numerical Approach IEEE Business Engineering and Industrial Applications Colloquium (BEIAC), p. 801-806, 2013

[8] Mahmud J, Evans S, Holt C, Adull Manan NF. Quantifying Skin Properties Using a Novel Integration Experiment-Finite Element Simulation and Skin Pre-Stretch Model Advanced Science Letters, American Scientific Publishers. p. 3155-3160, 2013

[9] Kao PH et al., A Microstructurally-Driven Model for Pulmonary Artery Tissue Journal Of Biomechanical Engineering, vol 133(5): p. 051002-051002, 2011

[10] Chen K, Weiland JD, Mechanical properties of orbital fat and its encapsulating connective tissue J Biomech Eng, vol 133(6): p. 064505, 2011 .

[11] Watton PN, Ventikos Y, Holzapfel GA, Modelling the mechanical response of elastin for arterial tissue Journal of Biomechanics, vol 42: p. 1320-1325, 2009.

[12] Chen Z, Diebels S. Nanoindentation of hyperelastic polymer layers at finite deformation and parameter re-identification Arch Appl Mech, 2012: p. 1041-1056.

[13] Mohd. Yusop SH, Investigating the Biomechanical Properties of Fresh Goat Skin, Natural Dried Skin \& Leather MSc Thesis, Faculty of Mechanical Engineering. 2016, Universiti Teknologi MARA.

[14] Mahmud J, Holt CA, Evans SL, An innovative application of a small-scale motion analysis technique to quantify human skin deformation in vivo Journal of Biomechanics, 43: p. 1002-1006, 2010.

[15] Shergold OA., Fleck NA, Radford D, The uniaxial stress versus strain response of pig skin and silicone rubber at low and high strain rates International Journal of Impact Engineering, vol 32(9): p. 1384-1402, 2006

[16] Kim B, et al., "A comparison among Neo-Hookean model, Mooney-Rivlin model, and Ogden model for chloroprene rubber", International Journal of Precision Engineering and Manufacturing, 13(5): p. 759-764,2012. 